\title{
(Re)Positioning Humanities in the Malaysian Higher Education Landscape
}

\author{
*MORSHIDI SIRAT \\ CHANG DA WAN \\ National Higher Education Research Institute, Universiti Sains Malaysia, \\ Block C, Level 2, sains@usm, No. 10, Persiaran Bukit Jambul, \\ 11900 Bayan Lepas, Pulau Pinang, Malaysia \\ *Corresponding author: morshidi@usm.my
}

Published date: 20 December 2018

To cite this article: Morshidi, S. and Wan, C.D. 2018. (Re)Positioning humanities in the Malaysian higher education landscape. KEMANUSIAAN the Asian Journal of Humanities 25(Supp. 1): 191-206, https://doi.org/10.21315/kajh2018.25.s1.10

To link to this article: https://doi.org/10.21315/kajh2018.25.s1.10

\begin{abstract}
This paper discusses the humanities and humanities education, which is inevitably embedded in the context of a re-assessment of the role and functions of universities in the current and future Industry 4.0 environment. While the humanities are generally considered as an embattled field since the emphasis on science and technology subjects in many developed and emerging economies, this paper does not subscribe to the notion of the humanities being handcuffed to a crisis narrative that are incomplete and disabling its future potentials. In the Industry 4.0 environment and perhaps an equivalent Society 4.0, there would be a dire need for society to envision a plan that would give top priority to the potential benefits of a higher education based on human-technology convergence. Failure to do so would mean humans would be overwhelmed by robotics and artificial intelligence (AI), peripheralising any disciplines that are considered as not relevant. In the context of Malaysia, the paper unpicks the issues and challenges in the provision of humanities education in the higher education landscape that begin to acknowledge and reclaim values and the human outcome in the higher education system still in the nascent stage of realising the importance of framing policies in the context of the human-technology convergence. This paper concludes by suggesting the way forward in re-positioning the humanities and humanities education, which would contribute to the idea of humanising higher education in the context of Industry 4.0.
\end{abstract}

Keywords and phrases: humanities, humanising higher education, human-technology convergence, Industry 4.0, neoliberalism 


\section{Introduction}

Universities around the world are experiencing a major identity crisis, and are going through a re-assessment of their roles and functions in the current and future higher education landscapes, especially with respect to their influences and impact on societal changes. Over recent decades, universities have been increasing in number and admitting more students than ever before - and yet there is also "unprecedented scepticism" about higher education in terms of the individual benefits to students and the collective contribution to society (Collini 2012). Universities are claimed to be the engines of technological and economic growth, and many developing nations are pouring huge resources into establishing and developing this engine of growth (Altbach et al. 2018), with the expectation that it will produce skilled knowledge workers for the knowledge economy, as well as generating new knowledge through research endeavours. However, many universities elsewhere continued to be seen as ivory towers that are elitist, backward-looking and selfindulgent (Collini 2012), and many economies, both developed and emerging, have a significant number of graduates who remain unemployed or under-employed.

The increasing student debts incurred by loans taken to pursue university education, particularly in the United States (US) but also elsewhere around the world including Malaysia, have further amplified the paradoxical situation of higher education. When discussing the relevance of academic disciplines and courses of study to the present and future world of work and society, the precarious situation of the humanities and the arts has never failed to be a significant topic in the discussion (see World Economic Forum 2016).

This paper explores the humanities as a discipline, which is inevitably embedded in the context discussed above, and further examines how humanities education in higher education can be repositioned for the future. It is important to note that this paper does not subscribe to the notion of the humanities being handcuffed to a crisis narrative which is incomplete and ultimately disabling for the future development of the discipline (see Burish 2018; Cassuto 2017; Classen 2014; McCumber 2016; Mulholland 2010; Stover 2017). The first section of the paper further explores the ongoing re-assessment of the roles and functions of universities vis-a-vis wider society. Having elaborated on the global context, the second section focuses on the humanities as a discipline specifically in the context of Malaysia, and further unpicks the issues and challenges in the provision of humanities education in the higher education landscape in Malaysia, which is beginning to acknowledge and reclaim values and human outcomes in the higher education system. The paper concludes by suggesting a way forward in repositioning humanities for the sustainable future of higher education in Malaysia. 
In the current Malaysian context, repositioning the humanities is a valid proposition. In the past, particularly in the late 1960s and early 1970s, this discipline attracted respectable enrolment numbers in public universities offering such subjects. It is noteworthy that right up to the 1980 s, humanities graduates were readily employed in industry and the public sector. The situation for the humanities as a discipline and the employability of graduates coming out of humanities education only became a great significant concern from the late 1990s (IPPTN 2003). National policy on science and technology has set the scene for the peripheralisation of humanities as a discipline and in the university curriculum. Now, in the current higher education landscape humanities education must reposition itself and reclaim its critical role, particularly with the current emphasis on humanising higher education. Mulholland (2010) rightly suggest that there must be a change in the vocabulary surrounding and attitude towards the humanities. For a start, there must be a cogent reassessment of what the humanities do and why they deserve to be maintained and expanded within the university system. This is the context of this paper.

\section{A Neo-Liberal and Economic-Centric Higher Education: Whither the Humanities?}

One of the major contributors to the identity crisis experienced by universities globally has resulted from infiltration by the neoliberal ideology. Neoliberalism is more than an economic policy; rather, as Harvey (2005) rightly postulates, it is a form of ideology that dictates and changes the fabric of our society. In the eyes of those who have embraced this ideology, neoliberalism is the "paragon of modern social relations", which assumes that "markets" are the focus of all aspects of our lives and places "profit over people" (Chomsky 1999; Giroux 2004).

This infiltration by the forces of neoliberalism has led to the monetisation of values, as well as introduction of markets and metrics into all spheres of life (Brown 2011, 2015). In the context of education, this has led to the "privatisation" of public goods and shifted the conceptualisation of education as individual goods away from society. Concurrently, this ideology has also forced the supremacy of the market on universities through the notion of fear of being left out of the competitive market, and has significantly changed the academic culture and landscape of higher education (Smyth 2018). This development, to a large extent, is contrary to the spirit of the humanities, where competition is not always the primary objective. Furthermore, cost-cutting and maligning teaching and research because they do not serve the "bottom line" in a commercially-driven and marketised higher education system is an affront to many disciplines in the humanities such as philosophy and the arts (Mulholland 2010). 
In a neoliberal environment, knowledge is therefore commodified, education becomes a business, and students are now customers who are purchasing and consuming education. One of the most obvious consequences of this shift has been the drastic commercialisation and marketisation of universities (Bok 2003), which has direct implications for the development of humanities education and will be discussed later in the paper. Along with institutional evolution, commercialisation and marketisation have also created chaotic circumstances in terms of the cost and financing of higher education. For instance, in the US, student debts increased by $1,120 \%$ from 1978 to 2014 , with the total debt exceeding the one-trilliondollar mark by 2014 (Rossi 2014). Student debts have overtaken household and credit card debts as the biggest proportion of debt in the economy, and this is effectively a time bomb that could paralyse the US economy, with worse potential consequences than the housing bubble of the mid-2000s.

Further, because of the economic- and market-centric focus of higher education, an economic logic began to dictate the development of universities. Whereas a university was traditionally an important institution in society for "conserving, understanding, extending, and handing on to subsequent generations the intellectual, scientific, and artistic heritage of mankind" (Collini 2012, 198), a university in a neoliberal and economic-centric framework becomes a "factory" that churns out "human capital" for the economy and society. The latter role is further intensified and given stronger emphasis in the context of a knowledge-driven or knowledgebased economy.

However, from the perspective of the humanities, learning in these subjects philosophy and classics, for example - is not about producing human capital. The humanities and humanistic enquiry are about moulding graduates as humanistic persons, holistic and balanced in their values, thinking and action. The conceptualisation of graduates as "products" or "human capital" is problematic in that these connotations de-humanise the discourse of education. It is extremely derogatory to see learned citizens in our society as mere products. Even more detrimental is the fact that higher education in a neoliberal framework becomes a form of certification of good workers and a measure of their intelligence, work ethics and conformity, using a "ruler" or yardstick determined by businesses and industries (Caplan 2018).

It is equally important to recognise that the paradigm of graduates as products or human capital will dictate that not all products will have the same value. There will be some products that are more valuable, profitable or employable than others. Hence, the economic logic may deem the reading of philosophy, classics, history 
or literature to be less useful, employable or profitable than other disciplines and specialisations in the sciences or professional fields.

The notion of "employability", which has become an important term in the discourse of an economic-centric higher education, is rooted in the neoliberal ideology of supply and demand in terms of graduates. This has led to the comparison of graduates from different disciplines, with some being seen as more in demand or more employable than others. Thus, in a market-centric higher education system, employability becomes the yardstick of performance or the key performance indicator for universities to measure the success of their graduates. Cascading this performance framework into the institution may lead to the sciences and professional fields being privileged over humanities and the social sciences.

\section{Industry 4.0}

The Fourth Industrial Revolution, famously termed Industry 4.0, in the policy discourse surrounding Malaysian higher education, refers to the "fusion of technologies that is blurring the lines between the physical, digital and biological sphere" (Schwab 2016). This recent hype surrounding Industry 4.0 is claimed to be a continuation of the industrial revolution that began in the late 19th century. This fourth phase of the industrial revolution is claimed to be different from the earlier phases, since it is centred on innovation in cyber-physical systems, including exponential technological breakthroughs in the fields of robotics, artificial intelligence (AI), nanotechnology, quantum computing, biotechnology, materials science and the Internet of Things (IoT). In comparison, the first phase of the industrial revolution was catalysed by mechanisation and steam power, the second phase by electricity and the third by computers.

More importantly, technological breakthroughs are claimed to be disruptive to the way our economy and society functions. It has been claimed that automation will result in job losses. Robots will replace humans for many jobs and functions, providing much greater consistency in quality and at the same time minimising costs. There was even a prediction that 101 jobs will be extinct by 2030 due to a process of "technological unemployment" (Frey 2014).

Regardless of whether Industry 4.0 is media hype or reality, the discourse has disrupted higher education and universities. The industry-centric tendency has pressured universities in terms of their role and position. Is it the case that the way of educating the next generation of learned citizens or training the next cohort of skilled workers in universities must change? 
Nevertheless, while this socio-economic phenomenon has been driven by technology, it has also presented an opportunity to rethink the role and purpose of university education. Although machines can replace humans in some facets of life, essential human capabilities such as critical thinking and creativity, as well as the "soul", are irreplaceable. Most crucially, these human capabilities and what we need as human beings are fundamentally grounded in humanities education through the reading and understanding of subjects such as philosophy, history, theology and literature. Interestingly, these are subjects that may be deemed irrelevant or not employable in an economic-centric framework for higher education, underlining the paradox of the role of the humanities. In an intensifying Industry 4.0 environment, with robots and AI overwhelming humans, the humanities should proactively "lend meaning, coherence, and beauty to our lives - in short [they] make us more fully human" (California State University 2016, cited in Campion 2017, 5).

\section{Futures of Higher Education: Humanising Higher Education}

The strategic intent for the future higher education landscape in Malaysia is being envisioned around the critical role and influence of Industry 4.0 on the future development of the national economy in a highly competitive world. In this context, the policy agenda is primarily about embracing Industry 4.0 as part of the call to revamp the Malaysian higher education system and redesign university curriculums. Specifically, the main concern is how to balance, navigate and harmonise human dimensions with technology in the context of the future development of the higher education landscape (IPPTN 2018). It is noteworthy that technological change has always been disruptive (The Guardian 2016), and this is likely to be the case in the future development of Malaysian higher education. This is the age of disruptions, and it will continue well into the future.

As noted earlier, Industry 4.0 refers to an environment that is developing rapidly, and which is driven by technologies that can be seen as "disruptive" emerging from trends such as the IoT, AI robotics and virtual reality (VR). All these developments are expected to have significant impacts on humanities education; the focus of Industry 4.0 is technology, and based on this view, technology is expected to dehumanise education. Alternatively, however, if we are to accept that in the Industry 4.0 environment a convergence of human and machine may take place, then it may also be expected that the distance between the humanities and social sciences and science and technology will be significantly reduced. Logically, then, teaching and research will necessarily have to cut across disciplinary boundaries and become interdisciplinary and multidisciplinary in their approach. 
These assumptions and conjunctures have been considered in envisioning and developing future scenarios for Malaysia's higher education (IPPTN 2018). Although the underlying rationale has been driven by the possible convergence of human and machine, within this context of convergence human and societal needs must take precedence over those of machines. In short, machines in the age of Industry 4.0 must exist to serve humankind, and not the reverse.

Since the early 1990s the fate of the humanities and humanities education in Malaysia was determined by the economic- and market-centric higher education system described earlier. The relevance of this embattled discipline re-emerged recently with media hype over the need for Malaysian higher education to embrace Industry 4.0. Following the permeation of Industry 4.0 into Malaysian development thinking, the Ministry of Higher Education has conceived "A Future Ready Curriculum Framework for Academic Programme Transformation" (Rose Alinda 2018) with emphasis on the following:

1. Linguistic, mathematical and technological literacies for all job roles in the future

2. Ensuring the breadth and depth of subject knowledge and the ability to make inter-disciplinary connections

3. Developing global citizenship values, including empathy and character

4. Non-cognitive employability skills such as problem solving, critical thinking, project management and creativity

Interestingly, within this framework, it is suggested that even within science, technology, engineering and mathematics (STEM) specific fields, employability depends in part on elements of strong creative and critical thinking and non-cognitive skills. Coincidentally, these elements are the core components of humanities and the main expected outcomes of any humanities education curriculum.

\section{Humanities and Other Disciplines}

The traditional comparison has pitted the humanities against the sciences, and perhaps STEM in particular, in terms of employability. These are two distinctive broad knowledge areas with contrasting epistemologies and methodologies. For example, knowledge formation in the humanities is more holistic and repetitive, where the aim is understanding and interpreting a phenomenon comprehensively; meanwhile, knowledge formation in the sciences is more theoretical, hierarchical and cumulative, aiming to find general regularities (KOPPA 2017). However, as Small (2013) pointed out, the recent increased influence of disciplines like 
economics, business and management has further underlined the emergence of social sciences within the existing dichotomy of the humanities and the sciences. Interestingly, discussion of the humanities seems inevitably tied to the sciences in the emerging higher education landscape of the future.

One of the "crises" or challenges that has confronted the humanities in higher education over the years has a direct relation to the sciences (Rosen 2014). For instance, in the US, during the Cold War period, huge resources were allocated for scientific and technological research. Resource allocation was further skewed after the Russians successfully launched Sputnik. Therefore, based on the logic that the best minds would follow the money, it was argued that the "cultural literacy and critical reflection that are the special provinces of the humanities and that were deemed indispensable for a strong democracy" had been starved during the Cold War period (Rosen 2014).

Emphasis on the hard sciences has repeatedly led to a neglect of the humanities. In the case of Malaysia, tremendous efforts have been made by the government to uphold a quota of 60:40 students in STEM and non-STEM subjects since the late 1960s although up until 2014 this target has not been achieved; only 45 percent of students are in the science stream (Azian 2015). As Malaysia aspires and works towards becoming a developed nation by 2020 , the emphasis on science and technology are seen as the critical initiative of the Vision 2020.

However, while we do not discount the importance of science and technology for Malaysia to become a developed nation, it is important to recognise that advances in science and technology are only one of the nine challenges outlined in the Vision 2020. Vision 2020 aims that:

Malaysia should be a united nation that is infused by strong moral and ethical values, living in a society that is democratic, liberal and tolerant, caring, economically just and equitable, progressive and prosperous, and in full possession of an economy that is competitive, dynamic, robust, and resilient. (Mahathir 1991, 22)

For this vision to be realised, nine essential challenges have been identified that need to be overcome; these are:

1. Challenge 1: Establishing a united Malaysian nation

2. Challenge 2: Creating a psychologically liberated, secure and developed Malaysian society

3. Challenge 3: Fostering and developing a mature democratic society 
4. Challenge 4: Establishing a fully moral and ethical society

5. Challenge 5: Establishing a mature, liberal and tolerant society

6. Challenge 6: Establishing a scientific and progressive society

7. Challenge 7: Establishing a fully caring society

8. Challenge 8: Ensuring an economically just society, in which there is a fair and equitable distribution of the wealth of the nation

9. Challenge 9: Establishing a prosperous society with an economy that is fully competitive, dynamic, robust and resilient

Examining these nine challenges carefully, we would argue that for Malaysia to become a developed nation by 2020, humanities is equally, if not more, important than science and technology. The social and cultural values and identity outlined in most of these challenges will require humanities education much more than science and technology. What are the philosophical underpinnings of a united Malaysian society? What social and cultural development will be able to shape and establish a moral and ethical society, or a fully caring society? What is the historical and political thinking that will be essential to establish a mature, liberal and tolerant society? What kind of economic paradigm will ensure an economically just and prosperous society? All these questions are rooted in the humanities, and yet science and technology has been argued to be the critical initiative for Vision 2020. This emphasis on science has consequently resulted in the neglect of the humanities.

The influence of and emphasis on science and technology have to a large extent been at the expense of humanities. An explicit example is the managerial framework used in higher education to manage and assess research and its productivity, which is predominantly drawn from the sciences. As Scott (2009, xv) outlined, "new public management" has encouraged a tighter and top-down performative and evaluative culture that relies heavily on the systematic use of citation indices, which "has been readily accepted in engineering, technology and other applied sciences and most natural sciences, but resisted in the social sciences and humanities". This acceptance by the sciences and resistance from the social sciences and humanities underlines the differences between them, but they have been put into a one-size-fits-all performative and evaluative framework. Typically, managerial audits of research productivity centre on "the number of competitive research grants, number of publications in what kinds of journals, and the number of research students completing within particular timeframe" (Smyth 2018, 116). 
It is well documented in the literature that modes of communicating knowledge differ considerably between the humanities and the sciences. For the humanities and a large part of the social sciences, books are the preferred mode of communication as opposed to journal articles (Becher and Trowler 2001; Griffith and Small 1983). Even in academic journals in the humanities, for example in the discipline of history, the number of book reviews in a journal may outnumber research articles (Steig 1986). The dominance of books and longer articles in the humanities, and parts of social sciences, is due to the fact that many of the arguments and discussions in these fields are complex and require the word length to illustrate the point, whereas articles are considered as a way of "getting started" in a research project or discussion.

Conversely, in the sciences as well as in social sciences dealing with topics that are increasingly becoming quantitative, such as economics and geography, there is a strong preference for a shorter and quicker mode of communication through journal articles. Quantitative research is particularly geared towards reporting particularities, instead of describing social phenomenon or complex arguments. More interestingly, in many technology-centred fields and topics, such as computer science, conference proceedings are the preferred mode to communicate new findings and knowledge, and even journals, where there is sometimes a period of several months to years between submission and publication, are less preferred. Nevertheless, due to the managerial audit framework borrowed from the sciences, which is further dictated by indicators used in rankings exercises which are themselves developed from citation indexes of journals, the disciplinary mode of communication in the humanities has become a less preferred output. In the long run, this may change the culture and the nature of work in the humanities.

The science-dominant framework has also influenced the way in which the next generation of disciplinary experts is being developed, and the kind of research being conducted in the field. For instance, the ethnographic research methodology, designed to develop new understanding and knowledge of different cultures, is a highly time-consuming activity where extended periods of fieldwork are necessary for thorough contemplation and analysis of the empirical data gathered. This method is core to the development of the disciplines of anthropology and sociology, as well as some specific research topics in education. Traditionally, much of the classic ethnographic work in the field of education has been conducted by doctoral students, but in recent years the requirement on students to finish within three or four years has deterred many from pursuing ethnographical work (Walford 2008). Similarly, academics and researchers in the field of anthropology have found it difficult to obtain funding, and have also struggled to be able to spend significant amounts of their time conducting full-fledged ethnographical fieldwork outside the 
university. Inevitably, research methods such as ethnography, which is implicit and with intangible outputs as compared to a clearly defined series of experiments in a laboratory, have suffered in the one-size-fits-all performative and evaluative framework used currently by universities and higher education system to audit productivity and research output.

\section{Repositioning Humanities and Humanities Education for Relevance}

For its future to be relevant, humanities as a discipline and humanities education in particular need to be repositioned in terms of what Campion (2017) referred to as the "importance of the humanities to a job-minded student body" (5). Arguably, if the main learning outcomes of humanities education are focused on honing graduates' critical thinking, research and writing skills, then more effort and careful consideration will be required from disciplinary scholars, researchers and teachers in humanities education if they are to articulate these skills as the top priority in terms of the characteristics of and outcomes for their graduates. In other words, there must be a clear articulation and prompt periodic alignment between what the humanities discipline is purported to be and the outcomes of humanities education. Ideally, there should be a feedback loop from the outcomes of humanities education to the discipline itself.

A second argument to support the relevance of the humanities, and thus their critical role in higher education, is related to what Campion (2017) termed the discipline's role in the "nurturing of the human spirit and reinforc[ing] the democratic values in ways that technical and professional training cannot" (5). In this respect, humanities education is better placed to play an important role in developing a system for the future that is built collectively and is based on values and competencies. In the Malaysian context, and moving forward, humanities education should consider the nine “Malaysia Future Proof" Skill Sets (Rose Alinda 2018) as follows:

1. Creativity and Innovation

2. Holistic, Entrepreneurial and Balanced

3. Resilience

4. Leadership

5. Compassion and Mindfulness

6. Values and Ethics

7. Flexibility and Adaptability

8. Critical Thinking and Problem Solving

9. Communication and Language Proficiency 
These skill sets are both values-based and competencies-based. The human dimension in the future Malaysian higher education system will be about repositioning, or rather, reclaiming the benefits of the continued existence of the humanities for the individual, the family and the community.

This repositioning must be demonstrated in the humanities education curriculum, and the outcomes of such a curriculum should be closely monitored. Humanities education and graduate outcomes should therefore be leveraged to convince policymakers, parents and students of the value of the humanities. Scholars and disciplinary experts should refrain from narrating a humanities discipline that is in a state of collapse or decline. There is a need to espouse an education model in which studying STEM subjects is good, but studying arts and the humanities is equally good for a values-based and cultured existence. As such, studying humanities should not be regarded as some "unaffordable luxury" (Willets 2013, 3).

\section{Repositioning Humanities Education for Synergy with Other Disciplines}

The repositioning of humanities education entails some form of synergy with other disciplines, ranging from the social sciences to STEM, in the development of programmes and curriculums in universities. Such a synergy, which crosses disciplinary boundaries, would ensure that teaching and research in humanities would not be in a silo, with interdisciplinary and multidisciplinary understanding further strengthening the core elements of humanities graduates and giving them insights, knowledge and competencies beyond one single discipline. In Malaysia, this synergy is not new or foreign; it was deliberately put in place in the establishment and subsequent development of Universiti Sains Malaysia. This was the first university to be fully established by Malaysia in 1969, and the recommendation of the Higher Education Planning Committee in 1967 was to focus on sciences. However, although the university was science-based in the beginning, the structure and approach of this university from its foundation was to provide a balance in terms of its focus. Hence, the School of Cultural and Community Studies (later renamed the School of Humanities) was established a year after the inception of the university in 1970, alongside the School of Comparative Social Sciences and the Centre for Educational Services, to provide a holistic and balanced focus in the education of students in a science-based university (School of Humanities n.d.). For an extended period of time students in the university were required to attend courses outside their major field of studies, underlining the synergistic approach to the humanities and sciences. 
The necessary repositioning of the humanities curriculum and education may also take a more structural approach by introducing a liberal arts programme in undergraduate education (Zakaria 2015), to include humanities subjects like philosophy, history and literature in the STEM curriculum. Alternatively, double major degrees that combine the humanities, the social sciences and STEM subjects could be introduced, but with very clear outcomes in terms of the skills and competencies of such an offering. In the past, some public universities have offered double major programmes combining one discipline in the humanities or social sciences with one discipline in the pure or applied sciences, to cater for specific purposes such teacher training. While the underlying concept of these programmes was laudable, their implementation often left much to be desired. Arguably, for a double major programme, and similarly for a double degree programme, the period of study needs to be extended for students to develop adequate skills and competencies. Such programmes, if properly conceptualised and implemented, would ensure relevance for future economic and societal changes. For instance, a student might concurrently pursue a double degree in engineering and anthropology, or in economics and history.

In addition, universities could also revamp their curriculums by stipulating a series of foundational courses in the first year of all undergraduate programmes, which should cover the basics of the humanities, social sciences and sciences for all undergraduates. An example of a foundational course could be an Introduction to Philosophy, which, instead of focusing on philosophers and the technicality of the subject, could be a course that guides students to systematically and critically think and internalise fundamental questions that arise in the course of their studies in university in relation to their humanity and citizenry. Introductory courses across all disciplines are essential, whereby undergraduate students in humanities should equally be exposed to courses such as Introduction to Science, Introduction to Society, and Introduction to Computing and Programming. Interestingly, the latter has been made a compulsory foundational course for all undergraduates at Harvard University (Rossi 2014).

Thus, a synergy of the humanities, STEM and the social sciences in the curriculum and learning will be a key step in repositioning the humanities as a discipline and humanities education within the future landscape of higher education, where the convergence of human and machine is soon to be a reality. In other words, we need scientists who understand the humanities as well as experts in various disciplines within the humanities who have basic knowledge of how science and technology work in order to plan for a sustainable future, and the repositioning of humanities education needs to proceed in synergy with other disciplines. 


\section{The Way Forward}

Paraphrasing Charles Dickens, Keen (2014) wrote that the history of the humanities has undergone the best of times and the worst of times. The recent past, including the digital revolution, has brought a range of cultural changes that are in many ways far more radical than those unleashed by the invention of the printing press over 500 years ago. Importantly, this digital revolution has made its presence felt far more swiftly (Keen 2014). Now and in the future, the humanities must deal with the challenges presented by Industry 4.0. This self-reflexive challenge is precisely what the humanities have always done best: highlighting the nature and the force of the narratives that have helped to define how we understand our society, its various pasts and its possible futures, and suggesting the larger contexts within which these issues must ultimately be situated (Keen 2014). It is important to recognise this as a valuable starting point as we begin to reposition the humanities in the future landscape of higher education, particularly in response to future roles when the convergence between human and machine is taking place.

Arguably, human-machine convergence should help to foster an energetic and sophisticated debate about the nature and value of the humanities, as well as what should be entailed in humanities education. This response must be treated as urgent in the current climate, both within and outside universities, where there does not seem to be much value placed on the role of the humanities in the Malaysian higher education landscape. Importantly, in this convergence scenario the critical contribution of the humanities pertains to the discourse about values and ethics in a future environment, which may well be an environment where robots and AI outnumber and overwhelm humans.

\section{References}

Altbach, P.G., Reisberg, L., Salmi, J. and Froumin, I. (eds.). 2018. Accelerated universities. Boston: Brill Sense.

Azian, T.S.A. 2015. STEM education: Policies and prospects toward achieving international standards and meeting national development needs. Paper presented at the International Science, Technology, Engineering and Mathematics: High Level Policy Forum on Evidence Based Science Education in Developing Countries, Kuala Lumpur, Malaysia, 26-27 May.

Becher, T. and Trowler, P.R. 2001. Academic tribes and territories (2nd ed.). Buckingham: The Society for Research into Higher Education and Open University Press.

Bok, D. 2003. Universities in the marketplace: The commercialization of higher education. Princeton: Princeton University Press.

Brown, W. 2011. Neoliberalized knowledge. History of the Present 1(1): 113-129. https://doi.org/10.5406/historypresent.1.1.0113 
2015. Undoing the demos: Neoliberalism's stealth revolution. New York: Zone Books.

Burish, T.G. 2018. Why we should spend more on humanities research in a high-tech world. The Chronicle of Higher Education (April 17).

California State University, Dominguez Hills. 2016. Welcome to the humanities program. www4.csudh.edu/humanities/ (accessed 28 May 2018).

Campion, C. 2017. Whither the humanities? Reinterpreting the relevance of an essential and embattled field. Arts and Humanities in Higher Education 17(4): 433-448. https://doi.org/10.1177/1474022217730819

Caplan, B. 2018. The case against education: Why the education system is a waste of time and money. Princeton: Princeton University Press. https://doi.org/10. 23943/9781400889327

Cassuto, L. 2017. The job-market moment of digital humanities. The Chronicle of Higher Education January 22: 1-4.

Chomsky, N. 1999. Profit over people: Neoliberalism and global order. New York: Seven Stories Press.

Classen, A. 2014. The challenges of the humanities, past, present, and future: Why the middle ages mean so much for us today and tomorrow. Humanities 3(1): 1-18. https://doi.org/10.3390/h3010001

Collini, S. 2012. What are universities for? London: Penguin.

Frey, T. 2014. 101 endangered jobs by 2030. https://www.futuristspeaker.com/businesstrends/101-endangered-jobs-by-2030/ (accessed 13 May 2018).

Giroux, H.A. 2004. Public pedagogy and the politics of neo-liberalism: Making the political more pedagogical. Policy Futures in Education 2(3\&4): 494-503. https://doi.org/10.2304/pfie.2004.2.3.5

Griffith, B.C. and Small, H.G. 1983. The structure of the social and behavioural sciences literature. Stockholm: Royal Institute of Technology Library.

Harvey, D. 2005. A brief history of neoliberalism. Oxford: Oxford University Press.

IPPTN (Institut Penyelidikan Pendidikan Tinggi Negara). 2003. Kajian masalah pengangguran di kalangan siswazah: Laporan akhir. Pulau Pinang: IPPTN.

2018. Constructing Malaysia's future higher education scenarios in the fourth industrial revolution. A framework for educational leaders to shape the future of higher education in a challenging and changing world. Pulau Pinang: IPPTN.

Keen, P. 2014. Imagining what we know: The humanities in a utilitarian age. Humanities 3(1): 73-87. https://doi.org/10.3390/h3010073

KOPPA. 2017. Publication culture in different disciplines. https://koppa.jyu.fi/avoimet/ kirjasto/en/library-tutorial/finding-sources/publication-culture (accessed 15 May 2018).

Mahathir, M. 1991. Wawasan 2020. Kuala Lumpur: Prime Minister's Department Malaysia.

McCumber, J. 2016. How humanities can help fix the world. The Chronicle of Higher Education (October 2).

Mulholland, J. 2010. It's time to stop mourning the humanities. The Chronicle of Higher Education (June 1). 
Rose Alinda, A. 2018. A future ready curriculum framework for academic programme transformation. Paper presented at the Excellence in Teaching and Learning Seminar Series 2/2018, Penang, Malaysia, 27 April.

Rosen, G. 2014. The humanities have a PR problem. Princeton Alumni Weekly (July 9).

Rossi, A. 2014. Ivory tower. Documentary film. Directed by Andrew Rossi. United States: CNN Films.

School of Humanities, Universiti Sains Malaysia. n.d. Background and philosophy. https://humanities.usm.my/index.php/discover-us/overview/backgroundphilosophy (accessed 29 May 2018).

Schwab, K. 2016. The fourth industrial revolution: What it means, how to respond. https://www.weforum.org/agenda/2016/01/the-fourth-industrial-revolution-whatit-means-and-how-to-respond/ (accessed 14 August 2017).

Scott, P. 2009. Foreword. In Academic research and researchers, eds. A. Brew and L. Lucas, xiii-Xviii. Berkshire: Society for Research into Higher Education and Open University Press.

Small, H. 2013. The value of the humanities. Oxford: Oxford University Press. https://doi.org/10.1093/acprof:oso/9780199683864.001.0001

Smyth, J. 2018. The toxic university. London: Palgrave Macmillan.

Steig, M. 1986. The origin and development of scholarly historical periodicals. Alabama: University of Alabama Press.

Stover, J. 2017. There is no case for the humanities. American Affairs 1(4): 210-224.

The Guardian. 2016. Fourth industrial revolution brings promise and peril for humanity. https://www.theguardian.com/business/economics-blog/2016/jan/24/4th-industrialrevolution-brings-promise-and-peril-for-humanity-technology-davos (accessed 28 May 2018).

Walford, G. 2008. The nature of educational ethnography. In How to do educational ethnography, ed. G. Walford, 1-15. London: Tufnell Press.

Willets, D. 2013. In the race for scientific prowess we mustn't leave the arts behind. The Guardian (18 August).

World Economic Forum. 2016. The future of jobs employment, skills and workforce strategy for the fourth industrial revolution. Davos: World Economic Forum.

Zakaria, F. 2015. In defense of a liberal education. New York: W.W. Norton \& Company. 